\title{
THE INTERACTION BETWEEN WORK AND HOME OF EMPLOYEES IN THE EARTHMOVING EQUIPMENT INDUSTRY: MEASUREMENT AND PREVALENCE
}

\author{
IZEL ROST \\ irost@barloworld-equipment.com \\ Barloworld Equipment \\ KARINA MOSTERT \\ Karina.Mostert@nwu.ac.za \\ WorkWell: Research Unit for People, Policy \& Performance \\ North-West University, Potchefstroom
}

\begin{abstract}
The objectives of this study were to determine the psychometric properties of a new work-home interaction instrument, the Survey Work-home Interaction-Nijmegen (SWING) in the South African context, and to determine the prevalence of work-home interaction. A cross-sectional survey was conducted among employees in the earthmoving equipment industry $(N=528)$. Structural equation modelling showed that a four-factor model fitted the data best. This factor structure was equivalent across important subgroups. Cronbach's alpha coefficients showed that all four factors were reliably measured. Paired-samples $t$-tests revealed that negative interference from work to home is more prevalent than negative interference from home to work, but that positive interference from the home domain is more prevalent than positive interference from the work domain.
\end{abstract}

Keywords:

Work-home interaction, construct validity, construct equivalence, reliability, prevalence

In the past decade organisations have focused with renewed interest on the interaction between work and family. This is mainly because of major changes that took place in the composition of the labour market, not only internationally, but also in South Africa. The workplace has become progressively diverse due to transformation developments, including Employment Equity and Affirmative Action legislation, impacting on the financial performance of organisations (Cavaleros, Van Vuuren \& Visser, 2002). These changes have resulted in an increased number of women and working couple families entering the workforce, thereby changing the traditional role of men (Brink \& De la Rey, 2001; Gerber, 2000; Smit, 1995; Smit, 2001; Schreuder \& Theron, 2001; Theunissen, Van Vuuren \& Visser, 2003; Wallis \& Price, 2003). As a result, one of the major challenges that organisations and employees face is the management of the integration of family and work demands (Brink \& De la Rey, 2001; Geurts \& Demerouti, 2003).

Work and family integration for employees has become vital as they are increasingly forced to deal with work and family demands simultaneously. Greenhaus and Beutell (1985, p. 77) define work-family conflict as "a form of inter-role conflict in which the role pressures from the work and family domains are mutually incompatible in some respect. That is, participation in the work (family) role is made more difficult by virtue of participation in the family (work) role". Work-family conflict is related to several organisational outcomes such as increased work stress, lower levels of commitment to the organisation, increased absenteeism, decreased job satisfaction, high turnover (intention of leaving the organisation), low levels of performance and fewer constructive perceptions of the organisation (Allen, Herst, Bruck \& Sutton, 2000; Duxbury, 2004; Duxbury \& Higgins, 2001; Geurts \& Demerouti, 2003; Grandey \& Gropanzano, 1999; Kirchmeyer \& Cohen, 1999). Consequently, organisations have realised that work-family conflict is an important concept to consider for the welfare of their employees, and that it is in the organisation's best interest to address work-family issues because this may result in the development and growth of intellectual capital and return on investment (Barnett, 1996; Kotzé, 2005; Parasuraman \& Greenhaus, 1999).

The importance of work-home interaction can also be seen in the earthmoving equipment industry. According to the Bureau of Labor Statistics, construction work, mining and agriculture were the three most dangerous occupations in the United States in 2000 (Injury Prevention Service, 2003). This industry has a competitive, stressful work environment and many workrelated stressors will likely be relevant to the work of managers, supervisors and professionals (Lingard, 2003; Smallwood, 1997). Employees are expected to work long hours, which causes stress and influences productivity (Goldenhar, Hecker, Moir \& Rosecrance, 2003; Lingard, 2003; Lingard \& Francis, 2005; Lingard \& Sublet, 2002). There is also constant pressure to improve safety, productivity and efficiency (Singh, 1997). Working under these stressful conditions can create fatigue in individuals and thus make it difficult for them to get actively involved in changing working conditions (Djebarni, 1996). Factors such as safety, a stressful working environment and long working hours may have major implications for employees, who could find it difficult to balance work and family demands.

Although it is important to investigate the work-home interaction of employees, research in this field has been characterised by several limitations. Firstly, the majority of research has focused almost exclusively on the negative impact of work on home (Carlson, Dacmar \& Williams, 2000; Netemeyer, Boles \& McMurrian, 1996; Stephens \& Sommer, 1996), while very few studies have addressed the reversed process (interference from the home domain on the work domain) or the possibility that the interaction between work and home can also be positive (Geurts \& Demerouti, 2003; Grzywacz \& Marks, 2000). Secondly, many instruments are available to measure negative work-home interaction. However, not many instruments exist for measuring positive workhome interaction (Carlson, Dacmar, Wayne \& Grzywacz, 2006; Kirchmeyer, 1992), and even fewer instruments are available to measure both negative and positive interaction.

Currently, two measuring instruments exist that measure both negative and positive interaction between the work and home domain (see Grzywacz \& Marks, 2000; Geurts et al., 2005). Although the instrument of Grzywacz and Marks (2000) measures negative and positive spillover, a concern is that some of its items confound work-family spillover with its possible consequences (e.g. fatigue and sleep quality) and antecedents (e.g. spouse's support). The other instrument, the Survey Work- 
Home Interaction-Nijmegen (SWING), was recently developed by Geurts et al. (2005). This questionnaire is theoretically based on the Effort-Recovery (E-R) Model (Meijman \& Mulder, 1998) and was designed to enhance and extend the existing knowledge on work-home interaction. The SWING differentiates between the direction (work $\rightarrow$ home and home $\rightarrow$ work) and the quality of influence (negative and positive).

Since no South African instrument that measures negative and positive interaction between work and home is available, the SWING seems to be a psychometrically sound instrument to use and to adapt for South African conditions. The SWING was successfully used in several studies in Europe (e.g. Bakker \& Geurts, 2004; Demerouti, Geurts \& Kompier, 2004; Montgomery, Peeters, Schaufeli \& Den Ouden, 2003; Peeters, Montgomery, Bakker \& Schaufeli, 2005; Van Hooff et al., 2005) and was validated extensively by Geurts et al. (2005). However, only one study could be found that investigated the psychometric properties of the SWING in the earthmoving equipment industry in South Africa (viz., Pieterse \& Mostert, 2005). This study confirmed the four-factor structure of the SWING and found it to be an equivalent and unbiased instrument for English and non-English speaking employees.

Although Pieterse and Mostert's (2005) study was an important initiative, their sample was relatively small $(N=326)$, exploratory factor analysis was used to determine the psychometric properties of the SWING and the equivalence was determined for only two language groups (English vs. other languages). Therefore, the current study seeks to investigate the psychometric properties of the SWING more intensively by using a more representative sample, by using the advantages of structural equation modelling (SEM) to test competing factor models and by testing the equivalence of the factor structure across six important subgroups (i.e. groups formed in terms of language, ethnicity, gender, education, marital status and parental status). In addition, the prevalence of work-home interference (WHI) and of home-work interference (HWI) were to be determined.

In view of the above, the objectives of this study are therefore: (1) to determine the construct validity, construct equivalence and reliability of the SWING by using SEM; and (2) to determine the prevalence of negative and positive work-home interaction.

The Survey Work-Home Interaction - Nijmegen (SWING) The SWING was developed at the Radboud University in Nijmegen, the Netherlands, to measure work-home interaction. This instrument is considered theoretically sound and is based on a strong theoretical perspective, namely the Effort-Recovery (E-R) model (Meijman \& Mulder, 1998). The E-R model describes by which mechanisms interaction can occurs between work and private life that can affect an individual's well-being (Geurts, Kompier, Roxburgh \& Houtman, 2003). The E-R model proposes that effort expenditure is associated with specific load reactions that developed within the individual. These load reactions can include physiological, behavioural and subjective responses and are, in principle, reversible. When the exposure to load is reduced, recovery can begin and the respective psychological systems begin to stabilise at a specific baseline level within a certain period of time (Drenth, Thierry \& De Wolff, 1998). The recovery process results in a reduction of fatigue and other stressful situations. However, recovery cannot occur unless the demands cease - otherwise the originally adaptive responses will develop into negative load reactions (e.g. strain, short-term psychosomatic health complaints and sustained activation) that may spill over to the home environment.

The presuppositions put forward by the E-R model can also enhance our understanding of positive work-home interaction, since effort expenditure may also be accompanied by positive load reactions. When individuals are able to keep their effort investments within acceptable limits by utilising opportunities for control and support (e.g. by alternating high-effort and low- effort, or unpleasant and pleasant tasks; by taking a "time out" when necessary; and by asking support from significant others such as a supervisor, colleagues or a spouse), energy resources may be recharged rather than exhausted. Furthermore, in order to stabilise energy generation, it is necessary to consume energy (Marks, 1977). People tend to find energy for the things they like doing and will produce rather than consume energy when engaging in positive experiences. This will result in tasks being completed with excellence and the creation of positive load reactions, which may influence the home environment in a positive way.

Based on the E-R model, Geurts et al. (2005, p. 322) define the work-home interface as "an interactive process in which a worker's functioning in one domain (e.g. home) is influenced by (negative or positive) load reactions that have built up in the other domain (e.g. work)". This definition implies four types of work-home interaction, namely negative WHI (when negative load reactions built up at work hamper functioning at home), positive WHI (when positive load reactions built up at work facilitate functioning at home), negative HWI (when negative load reactions developed at home impede functioning at work), and positive HWI (when positive load reactions developed at home facilitate functioning at work). The items of the SWING are divided into a four-response format which varies from 0 (never) to 3 (always).

Originally, the SWING consisted of 27 items. Nine items covered negative WHI, including five items that measured strain-based interference (e.g. "How often does it happen that you are irritable at home because your work is demanding?") and four items that covered time-based interference (e.g. "How often does it happen that you have to work so hard that you do not have time for any of your hobbies?"). Six items measured positive WHI, of which five items were self-developed; four items covered the transfer of skills learned at work (e.g. "How often does it happen that you are better able to keep appointments at home because your job requires this as well?"); two items captured the spillover of positive mood (e.g. "How often does it happen that after a pleasant working day/working week, you feel more in the mood to engage in activities with your spouse/family/friends?"). Six items were developed to measure Negative HWI (e.g. "How often does it happen that you have difficulty concentrating on your work because you are worried about your home situation?"), of which five were parallel to the negative WHI scale. Six items measured positive HWI, of which five items were self-developed and parallel to the five positive WHI-items; three items measured the transfer of skills learned at home (e.g. "How often does it happen that you take responsibilities at work more seriously because you are required to do the same at home?"); and two items covered the spillover of positive mood (e.g. "How often does it happen that you manage your time at work more efficiently because at home you have to do that as well?").

\section{The psychometric properties of the SWING}

Geurts et al. (2005) examined the construct validity of the SWING by comparing competing models for the relationships among the 27 items. Compared to three other competing models, the proposed model fitted the data best. This model identified the four expected dimensions (i.e. negative WHI, positive WHI, negative HWI and positive HWI), although five problematic items had to be removed. The final version of the SWING consisted of 22 items, of which 13 items were newly developed (Geurts et al., 2005). With regard to the construct validity of the SWING in South Africa, two South African studies obtained similar results. Pieterse and Mostert (2005) extracted four factors by means of exploratory factor analysis. Van Tonder (2005) investigated the construct validity of the SWING by using structural equation modelling (SEM). After modifications were made to the proposed model and three items were deleted, the final model fit was satisfactory. Both studies found that workhome interaction can be characterised as a four-dimensional construct. 
Geurts et al. (2005) used confirmatory analyses to test the construct equivalence across five Dutch samples and relevant subgroupings (i.e. gender, parental status and full-time/parttime status). They reported that the SWING items did not function differently within any of the five samples and subgroups, as was confirmed by invariant factor loadings, factor covariances and item error variances. Pieterse and Mostert (2005) used exploratory factor analysis with target rotations to determine construct equivalence. The construct equivalence of the four scales was not satisfactory because three items were problematic. After removing the three items, they demonstrated construct equivalence for the four factors of the two language groups (English and non-English groups). Based on these results, it can be proposed that the SWING has a four-dimensional structure (e.g. negative WHI, positive WHI, negative HWI and positive HWI) (Proposition 1a) and that this structure will be equivalent for the subgroups in this study (Proposition 1b).

Geurts et al. (2005) found Cronbach's alpha coefficients of the SWING to be acceptable (Negative WHI $=0,84$; Positive WHI $=0,75$; Negative HWI $=0,75$; Positive HWI $=0,81$ ). Pieterse and Mostert (2005) also found the SWING to be a reliable instrument, where Cronbach's alpha coefficients were acceptable for all four factors $(\mathrm{NHWI}=0,87$; NWHI $=0,79$; PWHI $=0,79$; and PHWI $=0,76)$. Van Tonder (2005) found that all the scales were reliable, although the Positive WHI scale had a Cronbach alpha coefficient of 0,67 . Based on these results, it can be proposed that the SWING has sufficient reliability (Proposition 1c).

\section{The prevalence of work-home interaction}

Various research and empirical studies indicate that negative interference from work to home is more prevalent than negative interference from home to work (Bond, Galinsky \& Swanberg, 1998; Frone, 2002; Geurts \& Demerouti, 2003; Grzywacz \& Marks, 2000; Montgomery et al., 2003). These findings suggest that workers are more prone to prioritise work over family matters, thereby reducing their effort investment at home rather than at work. This implies that the work domain is less flexible than the home domain (Frone, Russell \& Cooper, 1992; Gutek, Klepa \& Searle, 1991). Furthermore, the results of Geurts et al. (2005) indicate that the highest mean score $(M=1,15)$ was obtained for positive HWI, compared to the mean score of positive WHI $(M=0,81)$. The lowest mean score $(M=0,46)$ was obtained for negative HWI, compared to negative WHI $(M=0,86)$. In all the samples, negative WHI was more prevalent than negative HWI. Grzywacz and Marks (2000) also reported that positive spillover originated more often from home than from work. Based on these results, it is expected that negative interference will originate more often from work than from home (Proposition $2 a$ ) and that positive interference will originate more often from home than from work (Proposition 2b).

\section{RESEARCH DESIGN}

\section{Research approach}

A quantitative research approach, and more specifically a crosssectional design, was used to answer the research questions.

\section{Research method}

Participants and sampling procedure

A survey was conducted among employees in the earthmoving equipment industry $(N=528)$ in Gauteng, the Limpopo Province, Mpumalanga, the Northern Cape, the Western Cape, the Eastern Cape, Kwa-Zulu Natal and the North West Province (response rate $=53 \%$ ). Table 1 gives an indication of the characteristics of the participants that were included in the study.

According to Table 1 , the sample was predominately male (72\%); 62,3\% were White and 20,6\% were African. Most of the participants spoke Afrikaans (44,1\%) and English (36,4\%) and were married with children (50,4\%). With regard to age, most of the participants were born in the years 1970 to 1979 (26 - 35 years of age). A total of $41 \%$ of the participants held a Grade 12 certificate and $24,2 \%$ held a technical college diploma. Most of the employees in the industry worked full-time (78\%).

TABle 1

Characteristics of the participants

\begin{tabular}{|c|c|c|c|}
\hline Item & Category & Frequency & Percentage \\
\hline \multirow[t]{2}{*}{ Gender } & Male & 380 & 72,0 \\
\hline & Female & 141 & 26,7 \\
\hline \multirow[t]{5}{*}{ Race } & White & 329 & 62,3 \\
\hline & African & 109 & 20,6 \\
\hline & Coloured & 60 & 11,4 \\
\hline & Indian & 16 & 3,0 \\
\hline & Other & 2 & 0,4 \\
\hline \multirow[t]{5}{*}{ Age } & $1940-1949$ (56 - 65 years $)$ & 44 & 8,3 \\
\hline & $1950-1959(46-55$ years $)$ & 108 & 20,5 \\
\hline & $1960-1969$ (36 - 45 years) & 137 & 25,9 \\
\hline & $1970-1979$ ( 26 - 35 years) & 158 & 29,0 \\
\hline & 1980-1987 (18 - 25 years) & 63 & 11,9 \\
\hline \multirow[t]{11}{*}{ Language } & Afrikaans & 233 & 44,1 \\
\hline & English & 192 & 36,4 \\
\hline & Zulu & 18 & 3,4 \\
\hline & Tsonga & 6 & 1,1 \\
\hline & Sepedi & 30 & 5,7 \\
\hline & Sesotho & 12 & 2,3 \\
\hline & Setswana & 8 & 1,5 \\
\hline & Venda & 5 & 0,9 \\
\hline & Ndebele & 7 & 1,3 \\
\hline & Xhosa & 11 & 2,1 \\
\hline & Other languages & 1 & 0,2 \\
\hline \multirow{6}{*}{$\begin{array}{l}\text { Household } \\
\text { situation }\end{array}$} & Single without children & 81 & 15,3 \\
\hline & Single with children & 44 & 8,3 \\
\hline & Married without children & 77 & 14,6 \\
\hline & Married with children & 266 & 50,4 \\
\hline & Living with parents & 35 & 6,6 \\
\hline & Other & 18 & 3,4 \\
\hline \multirow{7}{*}{$\begin{array}{l}\text { Education } \\
\text { level }\end{array}$} & Grade 10 & 77 & 14,6 \\
\hline & Grade 11 & 217 & 41,1 \\
\hline & Grade 12 & 44 & 8,3 \\
\hline & Technikon diploma & 11 & 2,1 \\
\hline & Postgraduate & 16 & 3,0 \\
\hline & Technical/College diploma & 128 & 24,2 \\
\hline & Other & 1 & 0,2 \\
\hline \multirow{2}{*}{$\begin{array}{l}\text { Employment } \\
\text { status }\end{array}$} & Full time & 412 & 78,0 \\
\hline & Part time & 93 & 17,6 \\
\hline
\end{tabular}

Measuring instruments

The following questionnaires were used in the empirical study:

The Survey Work-Home Interaction - Nijmegen (SWING) was used to measure work-home interaction (Geurts et al., 2005). The SWING is a 22-item work-home interference instrument that measures four types of work-home interference, namely (1) negative WHI (eight items, e.g. "How often does it happen that you do not have the energy to engage in leisure activities with your spouse/family/friends because of your job?"); (2) positive WHI (five items, e.g. "How often does it happen that you fulfil your domestic obligations better because of the things you have learned on the job?"); (3) negative HWI (four 
items, e.g. "How often does it happen that you have difficulty concentrating on your work because you are preoccupied with domestic matters?"); and (4) positive HWI (five items, e.g. "How often does it happen that you take your responsibilities at work more seriously because you are required to do the same at home?"). All items are scored on a four-point frequency rating scale, which ranges from " 0 " (never) to " 3 " (always).

Biographical information was obtained with regard to gender, language, age, ethnicity, educational level, household situation (e.g. single, without children living at home/ married/living with a partner), working hours, permanent and part-time employment, use of annual leave, the contribution that the partner makes to the total household income; and the business unit and personnel area in which the employee operates.

\section{Research procedure}

After permission was obtained from executive management of the earthmoving company, the managers, human resources department and employee/employer committees were informed of the study during management meetings. Thereafter, all employees received paper-and-pencil questionnaires and return envelopes at their work that could be returned to the researchers involved. A letter explaining the purpose of the research accompanied the questionnaire. The employees were kindly requested to fill in the questionnaire in private and to send it to the Human Resources Department, where the researchers involved collected all the completed questionnaires. The participation was voluntary, and the confidentiality and anonymity of the answers were emphasised.

\section{Statistical analysis}

The statistical analyses were carried out with the SPSSprogram (SPSS Inc., 2005) and the Amos-program (Arbuckle, 2003). Structural equation modelling (SEM) methods, as implemented by Amos (Arbuckle, 2003), were used to examine the construct validity and construct equivalence of the SWING in terms of the maximum likelihood estimation method. A multi-group confirmatory factor analysis was used in order to test the construct equivalence of the factor structure and the equivalence of parameter estimates (i.e. factor loadings, factor covariances and item error variances) within each of the six important subgroupings, namely language (English vs. other African languages), ethnicity (White vs. indigenous groups), gender (males vs. females), education (employees with a school diploma vs. employees with a tertiary qualification), marital status (married vs. not married) and parental status (parents vs. not parents). In structural equation modeling, testing for the invariance of parameters across groups is accomplished by placing constraints on particular parameters. Therefore, the parameters are specified as being invariant (i.e. equivalent) across groups (Byrne, 2001).

The $\chi^{2}$ test and the following goodness-of-fit indices were used to summarise the degree of correspondence between the implied and observed covariance matrices: (a) $\chi^{2} / \mathrm{df}$ ratio; (b) the Goodness-of-Fit Index (GFI); (c) the Incremental Fit Index (IFI); (d) the Tucker-Lewis Index (TLI); (e) the Comparative Fit Index (CFI); (f) the Root Mean Square Error of Approximation (RMSEA). Values greater than 0,90 for relative fit indices (GFI, IFI, TLI and CFI) and lower than 0,08 for RMSEA are considered a good fit (Byrne, 2001; Hoyle, 1995).

Cronbach's alpha coefficients were used to assess the reliability of the scales and product-moment correlations were used to determine the relationship between the dimensions. Descriptive statistics (e.g. means and standard deviations) were used to describe the data. Paired-samples $t$-tests were used to determine the prevalence of work-home interaction.

\section{RESULTS}

\section{Construct validity}

In accordance with Geurts et al. (2005), the construct validity of the SWING was examined by comparing four models for the relationships among the 22 items. Model 1 proposes that all 22 items load on the same underlying latent dimension. This model implies that no distinctions can be made among the items in terms of direction (work $\rightarrow$ home vs. home $\rightarrow$ work) or quality (negative vs. positive) of influence. Model 2 ("direction model") is a two-factor model which distinguishes between items in terms of influence from work or influence from home (irrespective of its quality). Model 3 ("quality model") also distinguishes between two factors. The first factor includes all items that refer to positive interaction and the second factor includes all items that refer to negative interaction (irrespective of the originating domain). Lastly, Model 4 ("proposed model") represents the four-factor model and distinguishes between the four expected dimensions: negative WHI, negative HWI, positive WHI and positive HWI.

\section{TABLE 2}

GOODNESS-OF-FIT STATISTICS FOR THE COMPARISON OF FACTORIAL MODELS

\begin{tabular}{|c|c|c|c|c|c|c|c|c|}
\hline \multicolumn{2}{|c|}{ Model } & \multirow{2}{*}{$\frac{\chi^{2}}{2162,20}$} & \multirow{2}{*}{$\frac{\chi^{2} / d f}{10,35}$} & \multirow{2}{*}{$\frac{\text { GFI }}{0,61}$} & \multirow{2}{*}{$\frac{\text { IFI }}{0,49}$} & \multirow{2}{*}{$\frac{\text { TLI }}{0,43}$} & \multirow{2}{*}{$\frac{\text { CFI }}{0,48}$} & \multirow{2}{*}{$\frac{\text { RMSEA }}{0,13}$} \\
\hline $\mathrm{M}_{1}$ & $\begin{array}{l}\text { One-factor } \\
\text { model }\end{array}$ & & & & & & & \\
\hline $\mathrm{M}_{2}$ & $\begin{array}{l}\text { Two-factor } \\
\text { ("direction } \\
\text { model") }\end{array}$ & 1727,30 & 8,27 & 0,71 & 0,60 & 0,56 & 0,60 & 0,12 \\
\hline $\mathrm{M}_{3}$ & $\begin{array}{l}\text { Two-factor } \\
\text { ("quality model") }\end{array}$ & 989,91 & 4,74 & 0,83 & 0,79 & 0,77 & 0,79 & 0,08 \\
\hline $\mathrm{M}_{4}$ & $\begin{array}{l}\text { Four-factor } \\
\text { ("proposed } \\
\text { model") }\end{array}$ & 826,58 & 3,96 & 0,87 & 0,84 & 0,82 & 0,84 & 0,08 \\
\hline $\mathrm{M}_{5}$ & $\begin{array}{l}\text { Four-factor } \\
\text { ("re-specified } \\
\text { model") }\end{array}$ & 531,45 & 2,58 & 0,91 & 0,91 & 0,90 & 0,90 & 0,06 \\
\hline
\end{tabular}

Table 2 presents the fit-statistics of the four competing factorial models that were tested. Model 1 did not fit the data well $\left(\chi^{2}=\right.$ 2162,20; GFI, IFI, TLI and CFI $<0,90$ and RMSEA > 0,08). Model 2 ("directional model") and model 3 ("quality model") explained the associations among the items significantly better than model $1\left(\mathrm{M}_{2}\right.$ vs. $\mathrm{M}_{1}: \Delta \chi^{2}=434,90(\mathrm{~N}=528), d f=1,00, p<0,01$; $\mathrm{M}_{3}$ vs. $\left.\left.\mathrm{M}_{1}: \Delta \chi^{2}=1172,29 \mathrm{~N}=528\right), d f=1,00, p<0,01\right)$. However both models still fell short of what is acceptable. The fourfactor proposed model, which distinguished between the four proposed dimensions of work-home interaction, explained the associations among the items significantly better than the other three competing models ( $\mathrm{M}_{4}$ vs. M1: $\Delta \chi_{2}=1335,62(\mathrm{~N}=528), d f$ $=1,00, p<0,01 ; \mathrm{M}_{4}$ vs. $\mathrm{M}_{2}: \Delta \chi^{2}=900,72_{(\mathrm{N}=528)}, d f=1,000, p<$ 0,$01 ; \mathrm{M}_{4}$ vs. $\left.\mathrm{M}_{3}: \Delta \chi^{2}=163,43_{(\mathrm{N}=528)}, d f=1,00, p<0,01\right)$.

Although model 4 explained the associations among items significantly better than the other models, the GFI, IFI, TLI and CFI lower than 0,90 are indicative of failure to confirm the proposed model. In order to pinpoint possible areas of misfit, modification indices (M.I.) were considered which revealed that the two positive (Positive WHI and Positive HWI) and the two negative (Negative WHI and Negative HWI) latent factors should be correlated. Considering the high covariances (M.I. of Positive WHI and Positive HWI = 151,63; M.I. of Negative WHI and Negative HWI $=69,14)$, it was decided to re-specify the model in order to allow these factors to correlate. The modification indices also indicated a correlated error between item 3 and item 9 (M.I $=27,05)$. Compared with the M.I. values of the other error covariance parameters, this value is relatively high. It was therefore decided to allow the errors of this item pair to correlate. Model 5 fitted the data significantly better than model 
$4\left(\mathrm{M}_{5}\right.$ vs. $\left.\mathrm{M}^{4}: \Delta \chi^{2}=295,13(\mathrm{~N}=528), d f=3,00, \mathrm{p}<0,01\right)$. From a practical perspective, it also seems that the re-specified model indicates a relatively good fit $\left(\chi^{2} / \mathrm{df}<5,00\right.$; GFI, IFI, TLI and CFI $>0,90$; RMSEA $<0,08)$. Since this model fit was satisfactory and the results agreed with the theoretical assumptions underlying the structure of the SWING, no further modifications of the model were deemed necessary. Based on these results, it appears that the SWING has a four-dimensional structure that distinguishes between the direction (work-to-home and hometo-work) and quality (negative and positive) of influence, which supports Proposition 1a.

\section{Construct equivalence}

Next, the propositions relating to the equivalence for factor loadings, factor variances and covariances of the four-factor structure of the SWING were tested for the six relevant subgroupings. Statistically, the test for the equivalence of factor loadings and covariances involves the $\chi^{2}$ statistic to determine the difference in statistical fit between the unconstrained and constrained models. Non-significant differences between the models indicate statistical support for the propositions that were tested. Equivalence can also be examined by comparing the other indices (e.g. IFI, TLI, CFI and RMSEA) of the models that were compared. Such comparisons provide a test for equivalence at the practical level, where small differences are indicative of equivalence for the groups that were compared. The results are presented in Table 3.

Table 3 shows the results of analyses for testing measurement and structural equivalence across groups differing in terms of language, ethnicity, gender, education, marital status and parental status. As can be seen, the practical fit indices of the unconstrained models were very good, thereby supporting the equivalence for the number of factors. The indices for the constrained models also showed a very good fit and their values were very close to those for the constrained model. In addition, the differences between the models that were based on the $\chi^{2}$ value were also non-significant $(p<0,01)$. These results provide support for the equivalence in the pattern of factor loadings of the SWING across the subgroups, which provides support for Proposition $1 b$.

TABLe 4

DesCriptive STATISTICS, INTERNAL CONSISTENCIES AND PRODUCT-MOMENT CORRELATIONS FOR THE SWING DIMENSIONS

\begin{tabular}{lcccccc}
\hline Item & M & SD & $\alpha$ & NWHI & PWHI & NHWI \\
\hline Negative WHI & 1,00 & 0,57 & 0,86 & 1,00 & - & - \\
Positive WHI & 1,55 & 0,66 & 0,77 & $-0,17^{*}$ & 1,00 & - \\
Negative HWI & 0,55 & 0,53 & 0,71 & $0,37^{*+}$ & $-0,13^{*}$ & 1,00 \\
Positive HWI & 1,87 & 0,69 & 0,79 & $-0,15^{*}$ & $0,56^{*++}$ & $-0,18^{*}$ \\
\hline
\end{tabular}

* Correlation is statistically significant at the 0,01 level

+ Correlation is practically significant, $r>0,30$ (medium effect)

++ Correlation is practically significant, $r>0,50$ (large effect)

From the results in Table 4, it can be seen that all four scales are reliable when compared to the guideline of > 0,70 (Kline, 1999; Nunnally \& Bernstein, 1994), providing support for Proposition 1c. Furthermore, the correlations between the two negative scales $(r=0,37, p<0,01)$ and between the two positive scales $(r$ $=0,56, p<0,01)$ were the highest.

A post-hoc confirmatory analysis with SEM was conducted to exclude the possibility that the items belonging to the different negative and positive components actually tapped the same underlying dimension. Two models were tested for both the negative items and for the positive items. In the one-

TABLE 3

EQUIVALENCE OF THE FACTOR STRUCTURE FOR THE SUBGROUPINGS

\begin{tabular}{|c|c|c|c|c|c|c|c|}
\hline Model & $\chi^{2}$ & $\chi^{2} / \mathrm{df}$ & GFI & IFI & TLI & CFI & RMSEA \\
\hline \multicolumn{8}{|l|}{ Language } \\
\hline Unconstrained model & 765,82 & 1,86 & 0,88 & 0,91 & 0,91 & 0,90 & 0,04 \\
\hline Constrained model & 795,76 & 1,82 & 0,88 & 0,91 & 0,90 & 0,91 & 0,04 \\
\hline ( & \multicolumn{7}{|c|}{$\Delta \mathrm{X}^{2}=29,94_{(\mathrm{N}=528)}, \mathrm{df}=25,00(\mathrm{p}<0,01)$} \\
\hline \multicolumn{8}{|l|}{ Ethnicity } \\
\hline Unconstrained model & 852,71 & 2,07 & 0,87 & 0,89 & 0,87 & 0,89 & 0,05 \\
\hline Constrained model & 881,26 & 2,02 & 0,87 & 0,86 & 0,88 & 0,88 & 0,04 \\
\hline ( & \multicolumn{7}{|c|}{$\Delta \mathrm{X}^{2}=28,55_{(\mathrm{N}=528)}, \mathrm{df}=25,00(\mathrm{p}<0,01)$} \\
\hline \multicolumn{8}{|l|}{ Gender } \\
\hline Unconstrained model & 777,87 & 1,89 & 0,88 & 0,91 & 0,89 & 0,90 & 0,04 \\
\hline Constrained model & 828,39 & 1,90 & 0,88 & 0,90 & 0,89 & 0,90 & 0,04 \\
\hline ( & \multicolumn{7}{|c|}{$\Delta \mathrm{X}^{2}=50,52_{(\mathrm{N}=528)}, \mathrm{df}=25,00(\mathrm{p}<0,01)$} \\
\hline \multicolumn{8}{|l|}{ Education } \\
\hline Unconstrained model & 794,12 & 1,93 & 0,88 & 0,90 & 0,89 & 0,90 & 0,04 \\
\hline Constrained model & 836,78 & 1,92 & 0,87 & 0,90 & 0,89 & 0,89 & 0,04 \\
\hline ( & \multicolumn{7}{|c|}{$\Delta \mathrm{X}^{2}=42,66_{(\mathrm{N}=528)}, \mathrm{df}=25,00(\mathrm{p}<0,01)$} \\
\hline \multicolumn{8}{|l|}{ Marital status } \\
\hline Unconstrained model & 732,15 & 1,78 & 0,88 & 0,91 & 0,89 & 0,91 & 0,04 \\
\hline Constrained model & 754,26 & 1,73 & 0,87 & 0,91 & 0,90 & 0,91 & 0,04 \\
\hline ( & \multicolumn{7}{|c|}{$\Delta \mathrm{X}^{2}=22,11_{(\mathrm{N}=528)}, \mathrm{df}=25,00(\mathrm{p}<0,01)$} \\
\hline \multicolumn{8}{|l|}{ Parental status } \\
\hline Unconstrained model & 749,70 & 1,82 & 0,88 & 0,90 & 0,89 & 0,90 & 0,04 \\
\hline Constrained model & 777,08 & 1,78 & 0,87 & 0,90 & 0,90 & 0,90 & 0,04 \\
\hline$\square$ & \multicolumn{7}{|c|}{$\Delta \mathrm{X}^{2}=27,38_{(\mathrm{N}=528)}, \mathrm{df}=25,00(\mathrm{p}<0,01)$} \\
\hline
\end{tabular}


factor model $\left(\mathrm{M}_{1}\right)$ it was assumed that all the items load on one factor, while it was assumed that two different dimensions can be distinguished in the two-factor model $\left(\mathrm{M}_{2}\right)$. For the negative items, the results indicated that the two-factor solution $\left(\chi^{2}=\right.$ 183,$91 ; \chi^{2} / \mathrm{df}=3,47 ; \mathrm{GFI}=0,94 ; \mathrm{IFI}=0,94 ; \mathrm{TLI}=0,92 ; \mathrm{CFI}=$ $0,94$; RMSEA $=0,07)$ fitted the data significantly better than the one-factor solution $\left(\chi^{2}=429,28 ; \chi^{2} / \mathrm{df}=7,95\right.$; GFI $=0,86$; IFI $=$ 0,$82 ; \mathrm{TLI}=0,78 ; \mathrm{CFI}=0,82 ; \mathrm{RMSEA}=0,12 ; \Delta \chi^{2}=245,37(\mathrm{~N}=528)$, $\mathrm{df}=2,00, \mathrm{p}<0,01)$, indicating that negative WHI and negative HWI are two empirically different constructs (although they are related). The same was true for the positive items, where a twofactor solution $\left(\chi^{2}=107,53 ; \chi^{2} / \mathrm{df}=3,16\right.$; GFI $=0,96$; IFI $=0,95$; $\mathrm{TLI}=0,94 ; \mathrm{CFI}=0,95 ; \mathrm{RMSEA}=0,06)$ fitted the data significantly better than the one-factor solution $\left(\chi^{2}=283,61 ; \chi^{2} / \mathrm{df}=8,10\right.$; GFI $=0,88$; IFI $=0,84$; TLI $=0,80 ;$ CFI $=0,84$; RMSEA $=0,12 ; \Delta \chi^{2}=$ $\left.176,08_{(\mathrm{N}=528)}, \mathrm{df}=2,00, \mathrm{p}<0,01\right)$, implying that positive WHI and positive HWI are two empirically different (albeit related) constructs.

\section{Prevalence of work-home interaction}

Regarding the prevalence of work-home interaction, pairedsamples $t$-tests revealed that the employees reported higher levels of negative WHI $(M=1,00)$ than negative HWI $(M=0,55$, $\left.t_{(528)}=16,89, p<0,01\right)$; and higher levels of positive HWI $(M=$ $1,87)$ than positive WHI $\left(M=1,55, t_{(528)}=-11,81, p<0,01\right)$. These results provide evidence for Proposition $2 a$ and Proposition $2 b$.

\section{DISCUSSION}

The focus on work and family issues in the earthmoving equipment industry has become increasingly important for organisations and individuals, because this competitive industry operates in a stressful environment. However, only two measuring instruments measure the broad spectrum of work-home interaction, one of them being the SWING (Geurts et al., 2005). Relatively little information is known about the psychometric properties of the SWING when administered in the South African work environment, and no information is available regarding the prevalence of the four dimensions of work-home interaction. The objectives of this study were therefore to determine the psychometric properties of the SWING in order to establish if this instrument can be used to measure workhome interaction in a valid, equivalent and reliable way and to determine which of negative or positive interaction is more prevalent and which of work or home originated interaction is more prevalent.

With regard to the psychometric properties of the SWING, three aspects were investigated, namely (1) the construct validity, (2) the construct equivalence and (3) the reliability of the scales. With regard to the construct validity, it was proposed that work-home interaction (as measured by the SWING) is a four-dimensional construct that consists of negative and positive interference from work to home, and also negative and positive interference from home to work. In order to test this proposition, four competing structural models were tested for the relationships among the 22 items. The results indicated that the four-factor model explained the associations between the items significantly better compared to the alternative models. However, inspection of the standardised regression weights, modification indices and standardised residual covariances indicated that correlations between positive WHI and positive HWI should be allowed, as well as between negative WHI and negative HWI - indicating that these factors are in some way related to each other. Furthermore, errors were allowed to correlate between two items, namely item 3 ("How often does it happen that you find it difficult to fulfil your domestic obligations?") and item 9 ("How often does it happen that your work takes up time that you would have liked to spend with your spouse/family/friends?"). According to Byrne (1991), these parameters could represent non-random measurement error due to method effects associated with the response format of the instrument and therefore, their presence was not unexpected. Previous research with psychological constructs in general, and with measuring instruments in particular has demonstrated that the specification of correlated errors can often lead to substantially better fitting models (Byrne, 1991). Therefore, it was regarded as more sensible to include these parameters into the model, rather than to ignore their presence. After these modifications were made, the model fitted to the data satisfactory. This confirmed the propositions that workhome interaction can be characterised as a four-dimensional construct that distinguishes between the direction and quality of influence between work and home and these findings are congruent with previous research (Geurts et al., 2005; Pieterse $\&$ Mostert, 2005; Van Tonder, 2005).

South Africa is a multicultural society and the earthmoving equipment industry employs individuals from diverse cultural backgrounds. It is therefore important to determine the equivalence of the SWING for different language/ethnic groups because one cannot necessarily conclude that scores obtained in one culture are comparable across other cultural groups. Similarly, work-home interaction could be experienced in different ways by men and women, as well as by married and single individuals and parents and non-parents. However, in this study the structure of the SWING was equivalent for the relevant subgroupings (language, ethnicity, gender, education, marital status and parental status). In a similar vein, Pieterse and Mostert (2005) confirmed the construct equivalence of the four dimensions for two language groups (English and non-English) by using exploratory analyses, while Geurts et al. (2005) confirmed the construct equivalence of the SWING across subgroupings (i.e. occupation, gender, parental status and fulltime/part-time status).

With regard to the third aspect of the psychometric properties of the SWING, it was proposed that all the scales were sufficiently reliable. Acceptable Cronbach's alpha coefficients were obtained for all four scales, providing support for the reliability of the SWING. These results are in line with the findings of Geurts et al. (2005), Pieterse and Mostert (2005), and Van Tonder (2005), who all found acceptable reliability coefficients for the SWING. It can therefore be concluded that the SWING is a valid, equivalent and reliable instrument to use for different demographic groupings of employees in the earthmoving equipment industry in South Africa.

Findings regarding the prevalence of the WHI/HWI in this research revealed that work interfere more often with home than the other way around, but that positive interference originated more from home than from work. These findings support the results of Geurts et al. (2005), Grzywacz and Marks (2000) and Montgomery et al. (2003). The results may suggest proneness to prioritise work over family matters, resulting in reduced efforts at home; and that home activities are deemed more favourable than work activities. It could also be that the time to recover and to relax is more readily available in the home domain because energy are recharged rather than depleted at home.

\section{Recommendations and limitations}

With regard to the results obtained from this study, the SWING is recommended as a measuring instrument to measure workhome interaction in the South African earthmoving equipment industry. Furthermore, although the SWING demonstrated to be construct equivalent for the two language groups in this particular sample, English is regarded as the business language in the majority of South African organisations, and for a number of employees, English is a second language. When the SWING is used to measure WHI/HWI of employees for whom English is a second or even third language, it could be difficult for them to understand the content of the questions. Future research should therefore aim to translate the SWING into other official languages in order to include all relevant language groups when WHI/HWI research is conducted. 
Future research may enhance existing knowledge on the processes between the home and the work environment. Since this study was conducted among employees in a certain occupational group, future studies should investigate the psychometric proprieties of the SWING in other occupational groups, to allay possible suspicions that the use of modification indices may have capitalised on chance factors. Future research that uses longitudinal studies will also enhance assumptions regarding the relationships and consequences of work-home interaction with other relevant variables. A study of the processes of work-home interaction will ensure the better utilisation of its different and specific influences and outcomes in the earthmoving equipment industry. Furthermore, future research may enhance the existing knowledge of the interaction between the work and home domains, and may assist with the development and design of organisational policies to create a better integration of family and work roles within the earthmoving equipment industry.

\section{Author's Note}

The material described in this article is based on work that was supported by the National Research Foundation under reference number 20050801000025.

\section{REFERENCES}

Allen, T.D., Herst, D.E., Bruck, C.S. \& Sutton, M. (2000). Consequences associated with work-to-family conflict: A review and agenda for future research. Journal of Occupational Health Psychology, 5, 278-308.

Arbuckle, J.L. (2003). Amos 5.0. Chicago, IL: Smallwaters Corporation.

Bakker, A.B. \& Geurts, S.A.E. (2004). Towards a dual-process model of work-home interference. Work \& Occupations, 31, 345-366.

Barnett, R.C. (1996). Toward a review of the work/family literature: Work in progress. Boston: Wellesley College Centre for Research on Women.

Bond, J.T., Galinsky, E. \& Swanberg, J.E. (1998). The 1997 National Study of the Changing Workforce. New York: Families and Work Institute.

Brink, B. \& De la Rey, C. (2001). Work-family interaction strain: Coping strategies used by successful women in the public, corporate and self-employed sectors of the economy. South African Journal of Psychology, 31 (4), 55-61.

Byrne, B.M. (1991). The Maslach Burnout Inventory: Validating factorial structure and invariance across intermediate, secondary and university educators. Multivariate Behavioral Research, 26, 583-605.

Byrne, B.M. (2001). Structural equation modelling with AMOS: Basic concepts, applications and programming. Mahwah, NJ: Erlbaum.

Carlson, D.S., Dacmar, M.K. \& Williams, L.J. (2000). Construction and validation of a multidimensional measure of work-family conflict. Journal of Vocational Behavior, 56 (2), 249-276.

Carlson, D.S., Dacmar, M.K., Wayne, J.H. \& Grzywacz, J.G. (2006). Measuring the positive side of the work-family interface: Development and validation of a work-family enrichment scale. Journal of Vocational Behavior, 68, 131-164.

Cavaleros, C., Van Vuuren, L.J. \& Visser, D. (2002). The effectiveness of a diversity awareness training programme. South African Journal of Industrial Psychology, 28 (3), 50-61.

Demerouti, E., Geurts, S.A.E. \& Kompier, M.A.J. (2004). Positive and negative work-home interaction: Prevalence and correlates. Equal Opportunities International, 23 (1), 6-35.

Djebarni, R. (1996). The impact of stress in site management effectiveness. Construction Management and Economics, 14 (4), 281-293.

Drenth, P.J.D., Thierry, H. \& De Wolff, C.J. (Eds.). (1998). Handbook of work and organizational psychology ( $2^{\text {nd }}$ ed.). East Sussex: Psychology Press.
Duxbury, L. (2004). Dealing with work-life issues in the workplace: Standing still is not an option. The Don Wood Lecture in Industrial Relations. Ontario, Canada: Industrial Relations Centre.

Duxbury, L. \& Higgins, C. (2001, October). Work-Life balance in the new millennium: Where are we? Where do we need to go? CPRN Discussion Paper. Retrieved September 22, 2006, from the World Wide Web: http://www.cpm.org.

Frone, M.R. (2002). Work-family balance. In J.C. Quick \& L.E. Tetrick (Eds.), Handbook of occupational health psychology (pp. 143-162). Washington, DC: American Psychological Association.

Frone, M.R., Russell, M. \& Cooper, M.L. (1992). Prevalence of work-family conflict: Are work and family boundaries asymmetrically permeable? Journal of Organizational Behavior, 13, 723-729.

Gerber, H.M. (2000). Career development of SA professional women who take career breaks. South African Journal of Industrial Psychology, 26 (2), 7-13.

Geurts, S.A.E. \& Demerouti, E. (2003). Work/non-work interface: A review of theories and findings. In M.J. Schabracq, J.A.M. Winnubst \& C.L. Cooper (Eds.), The handbook of work and health psychology. Chichester, UK: John Wiley \& Sons.

Geurts, S.A.E., Kompier, M.A.J., Roxburgh, S. \& Houtman, L.D. (2003). Does work-home interference mediate the relationship between workload and well-being? Journal of Vocational Behavior, 63, 532-559.

Geurts, S.A.E., Taris, T.W., Kompier, M.A.J., Dikkers, J.S.E., Van Hooff, M.L.M. \& Kinnunen, U.M. (2005). Workhome interaction from a work psychological perspective: Development and validation of a new questionnaire, the SWING. Work \& Stress, 19 (4), 319-339.

Goldenhar, L.M., Hecker, S., Moir, S. \& Rosecrance, J. (2003). The "Goldilocks Model" of overtime in construction: Not too much, not too little, but just right. Journal of Safety Research, $34(2), 215$.

Grandey, A.A. \& Cropanzano, R. (1999). The conservation of resources model applied to work-family conflict and strain. Journal of Vocational Behavior, 54, 350-370.

Greenhaus, J.H. \& Beutell, N.J. (1985). Sources of conflict between work and family roles. Academy of Management Review, 10, 76-88.

Grzywacz, J.G. \& Marks, N.F. (2000). Reconceptualizing the work-family interface: An ecological perspective on the correlates of positive and negative spillover between work and family. Journal of Occupational Health Psychology, 5 (1), 111-126.

Gutek, B.A., Klepa, L. \& Searle, S. (1991). Rational versus gender role explanations for work-family conflict and strain. Journal of Vocational Behavior, 54, 350-370.

Hoyle, R.H. (1995). The structural equation modelling approach: Basic concepts and fundamental issues. In R.H. Hoyle (Ed.), Structural equation modelling, concepts, issues, and applications (pp. 1-15). Thousand Oaks, CA: Sage.

Injury update. (2003, March 31). A report to Oklahoma Injury Surveillance Participants. Retrieved from the world wide web: http://www.health. state.ok.us/PROGRAM/INJURY/ updates.pdf

Kirchmeyer, C. (1992). Perceptions of nonwork-to-work spillover: Challenging the common view of conflict-ridden domain relationships. Basic and Applied Social Psychology, 13, 231-249.

Kirchmeyer, C. \& Cohen, A. (1999). Different strategies for managing the work/non-work interface: A test for unique pathways to work outcomes. Work \& Stress, 13, 59-73.

Kline, P. (1999). The handbook of psychological testing ( $2^{\text {nd }}$ ed.). London: Routledge.

Kotzé, T. (2005). The nature and development of the construct "quality of work life". Acta Academica, 37 (2), 96-122.

Lingard, H. (2003). The impact of individual and job characteristics on "burnout" among civil engineers in Australia and the implications of employee turnover. Construction Management and Economics, 21 (1), 69-80. 
Lingard, H. \& Francis, V. (2005). Does work-family conflict mediate the relationship between job schedule demands and burnout in male construction professionals and managers. Construction Management and Economics, 23 (7), 733-745.

Lingard, H. \& Sublet, A. (2002). The impact of job and organizational demands. Construction Management and Economics, 21 (1), 69-80.

Marks, S.R. (1977). Multiple roles and role strain: Some notes on human energy, time and commitment. American Sociological Review, 42, 921-936.

Meijman, T.F. \& Mulder, G. (1998). Psychological aspects of workload. In P. J. Drenth, H. Thierry \& C. J. de Wolff (Eds.), Handbook of work and organizational psychology ( $2^{\text {nd }}$ ed.; pp. 5-33). Hove, UK: Erlbaum.

Montgomery, A.J., Peeters, M.C.W., Schaufeli, W.B. \& Den Ouden, M. (2003). Work-home interference among newspaper managers: Its relationship with burnout and engagement. Anxiety, Stress and Coping, 16 (2), 195-211.

Netemeyer, R.G., Boles, J.S. \& McMurrian, R. (1996). Development and validation of work-family conflict and family-work conflict scales. Journal of Applied Psychology, 81, 400-410.

Nunnally, J.C. \& Bernstein, I.H. (1994). Psychometric theory (3 ${ }^{\text {rd }}$ ed.). New York: McGraw-Hill.

Parasuraman, S. \& Greenhaus, J.H. (1999). Integrating work and family: Challenges for a changing world. Westport, CT: Praeger.

Peeters, M.C.W., Montgomery, A.J., Bakker, A.B. \& Schaufeli, W.B. (2005). Balancing work and home: How job and home demands are related to burnout. International Journal of Stress Management, 12 (1), 43-61.

Pieterse, M. \& Mostert, K. (2005). Measuring the work-home interface: Validation of the Survey Work-Home InteractionNijmegen (SWING) Instrument. Management Dynamics, 14 (2), 2-15.
Schreuder, A.M.G. \& Theron, A.L. (2001). Careers: An organizational perspective ( $2^{\text {nd }}$ ed.). Lansdowne: Juta.

Singh, S. (1997). State of the art in automation of earthmoving. Journal of Aerospace Engineering, 10 (4), 179-188.

Smallwood, J. (1997). Construction is a stressful industry: management. South African Builder, 889, 30.

Smit, R. (1995). Stres in die dubbelinkomstegesin: Is daar hoop op verligting? South African Journal of Sociology, 26 (4), 134-143.

Smit, R. (2001). Work-family spillover revisited: Is there hope for marital happiness in the dual-earner family. Koers 66 (4), $603-620$.

SPSS Inc. (2005). SPSS 14.0 for Windows. Chicago, IL: SPSS Inc.

Stephens, G.K. \& Sommer, S.M. (1996). The measurement of work to family conflict. Educational and Psychological Measurement, 56, 475-486.

Theunissen, B., Van Vuuren, L.J. \& Visser, D. (2003). Communication of job-related information and work-family conflict in dual-career couples. South African Journal of Industrial Psychology, 29 (1), 18-25.

Van Hooff, M.L., Geurts, S.A., Taris, T.W., Kompier, M.A., Dikkers, J.S., Houtman, I.L. \& Van den Heuvel, F.M. (2005). Scandinavian Journal of Work, Environment \& Health 31 (1), 15-29.

Van Tonder, H.P. (2005). A psychometric analysis of the Survey Work-Home Interaction Nijmegen (SWING) in a nursing environment. Unpublished master's dissertation, North West University, Potchefstroom Campus, South Africa.

Wallis, T. \& Price, L. (2003). The relationship between workfamily conflict and central life interests amongst single working mothers. South African Journal of Industrial Psychology, 29 (1), 26-31. 